KEVIN JOHNSTON, GRANDON GILL

\title{
STANDARD BANK: THE AGILE TRANSFORMATION ${ }^{1}$
}

Our goal: People in the workplace make decisions on the work based on data.

Josef Langerman, Head of IT Transformation for Standard Bank, reflected on the extraordinary transformation that his organization's IT group had recently experienced. Over the past three years, Standard Bank's IT group had changed from the relatively well accepted systems development lifecycle/waterfall model to a revolutionary large scale agile approach. The results had been gratifying. But it left a question unanswered. Now that things were starting to stabilize, what should be the next steps? The 154-year-old Standard Bank was the largest banking group in Africa, and the $5^{\text {th }}$ largest company headquartered in South Africa. The bank offered a range of corporate, business and personal banking as well as financial services. Its 49,000 employees served over 15 million customers, in 20 countries across the continent of Africa, as well as other countries scattered around the globe.

Standard Bank’s IT group, located within the company’s Johannesburg headquarters, had over 6000 employees. The group managed the bank's technology infrastructure--including a network of nearly 10,000 ATMs, its applications development, testing, deployment, maintenance and operations.

By 2014, the bank recognized that its IT performance was lagging industry benchmarks in productivity, turnaround time and employee satisfaction. Employing a "do it in-house” philosophy, it embarked on a major transformation. Abandoning traditional highly structured approaches to project management and development, it had adopted an agile philosophy that was most commonly seen in much smaller organizations and technology startups. The results had been impressive--productivity, cycle time and organizational health indicators had all risen dramatically. The group had also achieved substantial reductions in its budget. Even skeptics within the organization could not fail to be impressed.

Now, however, Langerman wondered about the future. He had been cautioned by his group's HR Culture Transformation Guide that rapid improvement could easily be followed by disillusionment. What could be done to keep the momentum going forward? Should the bank double down on the types of changes to culture, practice and training that had led to its success, or was it time to let things settle? And who should be guiding the change? Should the implementation continue entirely in-house, or should outside consultants--that were working in other areas of the bank--play a significant role? In the near future, he would need to present his recommendations to the group's CIO.

\footnotetext{
${ }^{1}$ Copyright (C) 2017, Kevin Johnston \& T. Grandon Gill. This case was prepared for the purpose of class discussion, and not to illustrate the effective or ineffective handling of an administrative situation. Names and some information have been disguised. This case is published under a Creative Commons BY-NC license. Permission is granted to copy and distribute this case for non-commercial purposes, in both printed and electronic formats.
} 


\section{Banking in South Africa}

Located at the southern tip of the African continent, South Africa was--in most respects--the most economically advanced country in Africa (see Exhibit 1). Some basic facts:

- The country's unit of currency was the rand, and at the time of writing the case, R1=\$.08.

- Over $70 \%$ of the population had access to an ATM or a bank branch within $15 \mathrm{~km}$ of their homes.

- Of the country's population of 55 million people, about $11 \%$ of adults were unbanked, and although the majority might have had access to basic banking services, most did not have the necessary financial literacy and skills to enhance their financial well-being.

- The major banking products used include savings accounts, credit and debit cards, and overdrafts or loans.

The 2016 FinScope survey revealed that $89 \%$ of adults in South Africa had some banking products (http://www.finmark.org.za/finscope). Many of the excluded were unemployed, the country's unemployment rate was $27.7 \%$ in the first quarter of 2017. The survey also found:

- Over $50 \%$ of adults were borrowers, however only $14 \%$ were borrowing from banks.

- Only 33\% of adults were savers, $15 \%$ saving with banks. There has been a trend of adults saving through informal stokvels (similar to credit unions).

- Roughly $14.5 \%$ of adults sent money to almost 13 million people regularly, either through cellphones or supermarkets.

Within South Africa, most rural and lower income markets are largely cash based. Cash in circulation in South Africa grew in the past ten years, and $60 \%$ of retail customers paid with cash.

There were four major banking groups operating in South Africa, of which Standard Bank was the largest in terms of assets. The four major groups reported combined headline earnings of $\$ 5,562,000,000$ (R72,300,000,000). The major banks reported a resilient earnings growth of $11 \%$ in 2016 with an $8.4 \%$ increase on headline earnings over 2015.

\section{Standard Bank}

Founded in 1862, Standard Bank was a full-service bank and, by many measures, was the largest financial institution headquartered in Africa. The bank operated across 20 countries in Africa. Listed on the Johannesburg Stock Exchange (JSE) in 1970, the bank was the 11th largest company in South Africa by market capitalization, and the 5th largest company with its head office in South Africa. A variety of facts about the bank are summarized in Exhibit 2.

Standard Bank had 24 subsidiaries, including those in 20 African countries, operations in the United Kingdom, Isle of Man, Jersey, Turkey and Russia. The Industrial and Commercial Bank of China acquired a 20\% stake in Standard Bank in 2007.

Standard Bank offered a wide range of banking services, divided into personal and business. Under personal services, the bank offered a range of savings and investment products including credit cards, unit trusts (mutual funds), foreign exchange, home loans, vehicle and asset finance, trusts, estate administration and insurance. The bank offered many self-service banking options including internet and cellphone banking. Business banking solutions included business accounts, borrowing, investments, insurance, and some customizable products to cater for niche business sectors. 
The bank was led by two co-CEOs: Ben Kruger and Sim Tshabalala. Reporting to the co-CEOs were the CFO, executives heading the banking divisions (Personal and Business, Corporate and Investment, and Wealth, Africa), and executives heading the support divisions (CIO, Compliance, Risk, Change, and Secretary). The CIO, Brenda Niehaus, headed the IT Group which managed and ran IT for the entire business.

\section{Standard Bank IT Group}

Located in Johannesburg, the largest city in South Africa, the Standard Bank IT Group employed about 6000 people. The group has been headed up by Group CIO Brenda Niehaus since 2013. The organizational structure of the IT Group had 12 executives reporting to the Group CIO as shown in Exhibit 3. The 12 included the Chief Technical Officer who managed 4,500 people, and was responsible for Service Delivery, Infrastructure, IT Planning, IT Architecture, Development, and Data. The Chief Operating Officer (COO) managed about 180 people including the Project Management Office (PMO), and software licensing. There were four business unit CIOs, one for each major business unit: Retail Banking, Investment Banking, Wealth Management, and Africa banking. The six support executives managed Risk, Audit, Procurement, Finance, Human Resources and Payments. The majority of the Group IT was housed in an office block in central Johannesburg consisting of 9 floors linked through central escalators. Approximately 500 customer facing staff, who reported to the business unit CIOs, were housed in a building in Rosebank, about 10 kilometers away, and about 250 staff were located in the two remote data centers outside of Johannesburg.

Standard Bank Group IT ran over 2,500 software systems, supporting 8,815 Automatic Teller Machines (ATMs) across Africa, and managed over 500 IT projects. There were over 500 Project Managers, and a PMO of 120 people. The two data centers housed six IBM mainframes plus over 12,500 Windows servers, 2500 UNIX servers and 1000 LINUX servers. Most of the servers were virtualized and additional servers were hosted in the cloud. The bank used a wide variety of technology, a mixture of old and new. Supported programming languages for newer development activities included Java, C and SAP ABAP, along with Swift and Objective C for mobile development. Many programmers also worked with Cobol, particularly on the mainframes. Oracle, DB2, MS-SQL and Sybase were the most used databases, but the bank used several others for specialized applications, including MongoDB for data warehousing.

\section{IT Transformation}

The decisions that currently faced Langerman were largely a consequence of a major transformation in the bank's approach to application development, delivery and operations that had taken place over the prior three years.

\section{Background}

Prior to 2014, Standard Bank’s IT Group delivered applications using techniques that paralleled those used by much of the global banking industry. Employing the systems development lifecycle (SDLC), also known as the waterfall model, the approach was built around a system of specific milestones and handoffs. As shown in Exhibit 4, this model treated the development process as a series of discrete activities (stages), each of which needed to be completed before the next stage could commence.

The SDLC's had been the mainstay of large organizations with substantial support activities--as would be typical in the banking industry--for more than 40 years. It originated in a period--the late 1960s and early 1970s--when software development experienced a crisis. The more ad hoc development approaches used 
in the 1960s tended to fail for large, complex systems. Far too frequently, such systems experienced major cost and time overruns. Even when completed, users within the organization would sometimes refuse to use the system since it did not appear to meet their needs. Under the SDLC, the chaos of the software crisis was replaced by a command-and-control system intended to promote orderly development. The associated cost was long development cycles--often three or more years for large applications--and reduced flexibility. As such, it was best suited for stable technology and business environments.

At Standard Bank, the SDLC was implemented in conjunction with project methodologies and resource pools. The different categories of IT professionals, such as developers, testers, architects, business analysts and project managers, consisted of both in-house and contract employees. As projects came online, personnel were assigned from the pools. The object was to fully utilize all available resources, with contractors coming and going to meet shifting project demand. A practical consequence of this approach was that individuals were often assigned to multiple projects.

Further complicating the process, the bank's previous CIO came to the firm with a background in European IT. As such, he promoted extensive offshoring to India and other countries for activities such as testing. While the economics of offshoring tended to be quite favorable in Europe and the U.S.--owing to the high cost of labor--they were much less so in South Africa. Moreover, providing employment was seen as an important social good in the country. Thus, in addition to adding to the complexity of application development, the benefits of offshoring were unclear. When replaced by the new CIO, Brenda Niehaus, the group decided to bring as many offshored activities back into the bank.

When Niehaus became CIO in 2013, she launched a systematic investigation of the IT department's performance. Working with McKinsey, the global consulting firm, the results suggested that the bank's IT performance was well below that of competing banks. Among the findings, the average time to deliver applications was well over 300 days--more than twice that of competitors. When compared with European benchmarks, overall performance was 12\% below the worst performing bank. The group's Organizational Health Indicator (McKinsey's measure of employee engagement and satisfaction) was at the very bottom of the third quartile. McKinsey also estimated that at least $30 \%$ of the group's activities failed to add value either to the bank's customers or its internal processes. Examples of problems from an internal bank presentation are shown in Exhibit 5.

Karl Fuchs, an Agile Transformation Actor \& Coach within the IT department, identified a number of sources of the problem. Most of these were directly related to the group's use of the SDLC and project management approaches. These included:

- Long lead times, since new projects could not be started until resources became available in the pool, and projects were not routinely prioritized.

- Multiple handoffs, many of these were a direct consequence of the stages of the SDLC, and the various substages that had become practice at the bank as its development methodology had evolved.

- Idle time, resulting from systems sitting in stasis while waiting to move from stage to stage. To try to ensure resource utilization, developers were often assigned to multiple projects. This led to another problem, frequent multitasking, which proved to be a drain on efficiency.

- Silos, in which one area of IT did not realize what other areas were doing. Among other concerns, it meant that projects and functions attempted to locally optimize their use of resources without consideration for the global needs of the bank.

- Defects in production software, resulting from developers and testers rushing software into production in order to avoid falling behind on project schedules. 
- Budget overruns, as the inefficiencies of the process led to manpower demands in excess of what was originally projected for most projects.

More broadly, the system that was in place encouraged developers to think of Standard Bank business units as "the customer." For software that interfaced with the bank's business or with consumers, this led to development that often failed to take into account the actual needs of the bank's true customers.

\section{Early Transformation Activities}

Given the growing perceptions that the existing SDLC model was unworkable, Niehaus instituted a program known as Accelerate intended to identify challenges and implement solutions. In parallel, some business units began to experiment with alternative approaches.

\section{Accelerate}

The Accelerate initiative began with McKinsey's systematic study of the bank's existing IT processes, the results of which were previously noted. Lyndsay Wood, the bank's Program Director for Accelerate, described the initiative as building on four distinct pillars:

1. Quality of service

2. Responsiveness to market

3. Affordability

4. Sustainability

Within this initiative, priorities were categorized as dealing with people, financial management, and technology. On the technology side, the group focused on a variety of areas. These included moving towards a next generation infrastructure to replace the banks aging servers and network technology. Another ongoing initiative was focused on simplifying the application landscape to reduce the number and complexity of the $2500+$ applications that were currently managed by the bank. A centralized software asset management system was acquired, allowing the bank to more effectively manage its licenses. Collectively, these helped the bank move towards its goal of reducing nearly $\$ 300,000,000$ (more than $\$ 3$ billion rand) from its IT budget, bringing it more in line with its competition.

On the people side, the challenge of achieving significant financial savings was more difficult. The inefficiencies of the project management approach that existed at the time were widely recognized. By its very nature, it led to cycles of expansion and contraction in staff and contractors, depending on the number of projects underway. In parallel with this, efforts to centralize control were often followed by efforts to decentralize control followed by efforts to centralize control--a never ending cycle as the organization attempted to find the right balance.

Early in the Accelerate initiative, it became clear that the only way to address the problem faced by the IT group was to achieve a transformation in how its activities were conducted. What was less clear initially was what the nature of that transformation needed to be.

\section{SBG Mobile}

As Niehaus surveyed the organization, a particularly interesting case study was identified in the area of mobile devices. The group that developed and deployed mobile apps was SBG Mobile, and happened to be located in a separate building. In the 2009-2010 period, SBG Mobile had initiated agile practices for all its activities. These practices included: 
- Tight collaboration with actual users of the products it developed.

- Rapid releases of product versions, each improving on prior releases in small increments.

- Adoption of highly transparent and collaborative programming practices, with frequent meetings to assess progress.

In addition to application development, the group moved towards a team-based approach that emphasized products rather than activities. Groups that developed an app would also test it and participate in moving it into production. These practices dramatically reduced the number of handoffs and delays (e.g., waiting for signoffs) that were intrinsic to the SDLC.

The results of these practices presented a stark contrast to the prevailing practices of the IT Group. SBG Mobile could release many versions of an app--often dozens--during the time period that it took the IT Group to build a single release. The evolving feature set of each product was much more tightly coupled with user needs. Cases of project abandonment, frequently encountered in the bank, were rare.

There was a caveat to these benefits, however. SBG Mobile apps tended to be smaller and less complicated than many of the bank's main applications. There was always a question as to the degree that the techniques would be scalable. Nevertheless, the early successes in mobile apps development led some areas of the IT Group to begin investigating them seriously. The first of these was Internet Banking. They were followed shortly thereafter by the larger Core Banking group.

\section{Moving Towards Broader Adoption}

As the strengths and challenges associated with agile development began to be recognized across the IT group, a need to consider a large-scale transition to agile methods was recognized. Before the transformation could even be considered, however, new philosophies of working and development needed to be instilled in the workforce.

In 2015, the bank brought in consultant Steve Bell, co-author of Lean IT, to look at its processes. He helped to facilitate an off-site value stream analysis. In this analysis, participants placed color coded sticky notes on a wall to indicate all the steps, including reviews and signoffs, associated with the design, development and release of an application. The typical application took up more than a full wall and involved hundreds of different activities (see Exhibit 6). Any objective observer could see that the process was too complicated to work properly. About half way through the week-long meeting, Niehaus joined the participants. According to Fuchs, she reported being shocked at just how fundamentally broken the existing SDLC-driven processes were. Incremental changes around the edges of the system no longer seemed to be an option.

A movement started within the group to start working using lean design principles. These principles included the use of small teams targeting the development of an MVP--very consistent with the philosophy of agile programming. The first area to test the approach was the group that developed applications for ATMs (automated teller machines). The preference of this group was to develop its own approach to lean, rather than relying on the guidance of outside consultants. This approach succeeded, and the preference for managing the transformation in-house became widely shared across the organization.

By late 2015, pockets of successful lean/agile development practices had emerged within the IT Group. Unfortunately, these early successes did not answer the broader question: To what degree could these practices scale to enterprise-level systems? To address this, larger frameworks and a new way to approach work needed to be instituted. 


\section{Scaled Agile Framework (SAFe)}

As the team-based development continued to gain momentum, the need for a broader organizing philosophy was recognized. The particular framework adopted was Leffingwell's Scaled Agile Framework (SAFe) (see http://www.scaledagileframework.com/). The SAFe framework is a proven, publicly available framework intended to allow Lean/Agile techniques--most commonly associated with smaller application development--to be employed in the context of large integrated systems. SAFe is a knowledge base for implementing Lean-Agile software and systems at scale. Exhibit 7 provides an overview of the SAFe framework, SAFe also provided descriptions of roles and responsibilities. Many corporates were using SAFe, including Cisco, Philips, HP Enterprises and Accenture. SAFe was continually being enhanced and upgraded, version 4.5 being current at the time of the case.

\section{Elements of the SAFe}

The SAFe was based around a system of layers and units intended to allow applications to be broken into pieces small enough to be handled by teams of a manageable size. SAFe was principles-based, and had nine core beliefs as seen in Exhibit 8. SAFe's four core values of alignment, built-in quality, transparency and program execution directed action and behavior.

- Alignment meant teams valued alignment to the organization's goals and values above team and individual objectives.

- Built-in quality required each element of a solution to meet quality standards at each iteration, while delivering high value to customer satisfaction.

- Transparency required all individuals to openly share progress and facts; it requires high levels of trust as staff are empowered to make decisions and act.

- Program execution required value to be delivered routinely and predictably.

\section{SAFe Levels}

In its original form the SAFe was organized into four organizational levels, plus a foundation layer. It was later modified to three levels, the form that Standard Bank utilized.

At the top was the Portfolio level. This level coordinated and funded all development initiatives in the organization, and provided necessary governance based on strategic themes. Applications and components were organized and prioritized, and viewed as pieces of a value stream--where "value" was assessed from the perspective of the customer. Each value stream assisted the organization to realize a strategic theme. Rather than referring to these elements by names like programs and applications, the SAFe referred to them as epics, collections of capabilities that offered value to the customer, and enablers, components needed to support the epics. A key aspect of the portfolio level was establishing priorities.

Below the value stream level was the program level. At this level, development was viewed in terms of features that supported the epics and enablers of the higher level. This level required many Agile Release Trains (ARTs) to be synchronized in order to develop large complex solutions. ARTs consisted of selforganizing teams of trained people from cross functional Agile teams who developed and delivered solutions. Program Increment (PI) planning was a face-to-face event which informed and aligned the ARTs. 
The bottom layer of the SAFe was the team level, based on Agile teams. This was the level at which actual development took place. Development was organized into stories that supported features. These stories roughly corresponded to "use cases" in other development methodologies. Each Agile team was responsible for delivering value in a series of pre-defined time slots (called sprints).

The foundation layer contained elements to support the process, such as core values, communities of practice, academies, links to academia and so on.

At Standard Bank the SAFe portfolio and value stream levels were combined. That led to a simplified version of the SAFe, as shown in Exhibit 9.

\section{New Ways of Work (NWOW)}

Implementing SAFe required a fundamental rethinking of how work was conducted within Standard Bank IT. This involved a change in overall work philosophy, a change to working practices and a comprehensive training program.

\section{Resource Utilization vs. Flow}

Broadly speaking, prior to the transformation the project management approach emphasized resource utilization. Under this approach, the pools into which the technical staff was organized--architects, developers, testers, business analysts, project managers and business analysts--were the source of available resources. As new systems were initiated, managers drew resources from these pools. The theory was that in the long run, these pools could be resized to match the demands of the projects under development. In the short run, however, the goal was to fully utilize available resources. This could require bringing new projects online to ensure that pools with extra resources were fully utilized.

As noted previously, this approach led to numerous inefficiencies. Low priority projects were sometimes launched and subsequently abandoned, based mainly on the need to keep technical staff occupied. Individuals might find themselves assigned to multiple projects--half a dozen was not uncommon--as projects became active and then paused (e.g., while waiting for sign offs). This produced a constant state of attention switching that drained productivity in order to ensure staff was fully occupied. Project managers could be assigned to multiple areas, limiting the degree to which they could develop expertise that could be transferred from project to project.

In order to implement the SAFe, an entirely new philosophy of development and production needed to be instilled. The problem with $100 \%$ resource utilization was that it often limited the flow of activity. Langerman used the analogy of a highway. When the highway reaches its capacity limit in terms of the number of vehicles it can hold, traffic tends to slow to a standstill (see Exhibit 10). What the group needed to focus on was maximizing the flow of applications and services. To achieve this, the bank needed to change its focus from resource utilization to flow. To achieve this, it would need to establish a model that fixed capacity at some optimal (or at least highly productive) level, and then prioritized tasks (i.e., epics and enablers, as they were called in the SAFe), so that they were addressed at a rate that matched capacity.

One advantage of the fixed capacity model was that it tended to achieve release of products at a more predictable rate than the project-driven approach. It also allowed organizational priorities--established at the SAFe portfolio level--to drive the overall pattern of activity. A large long-term benefit was that it encouraged a more stable workforce, as capacity was expected to change only slowly over time. This stability provided two important benefits: 1) It reduced the need for periodic retrenchments (i.e., layoffs) 
that had been common in the prior system, and 2) It reduced the knowledge loss and need for extensive training of new staff--both of which were particularly expensive in an IT context.

\section{Work Practices}

Adopting the SAFe model required numerous changes to how work was conducted. An organizing framework was adopted to guide this overall change in organizational culture. As shown in Exhibit 11, this framework was strongly influenced by both practice and research in agile development, organizational change and the social sciences.

One dimension of this was the adoption of lean and agile principles, as shown in Exhibit 12. At the heart of these principles was a focus on customer needs and, in particular, a degree of adaptability that was notably absent from the SDLC--by design, since the freezing of specifications was a high priority in structured development.

Another dimension was the focus on collaborative and transparent teams--referred to by the bank as selfregulating teams (see Exhibit 13). Unlike project teams, which tended to be organized in top-down fashion, agile teams met frequently for short periods of time in order to achieve transparency and ensuring many eyes were on each problem encountered.

To achieve effective teamwork in an agile world, the notion of a leader needed to be transformed. Project leaders typically worked through command and control. Leadership in an agile world was much more likely to take the form of facilitation and coaching. Rather than leadership positions, individuals would take on roles that could change from project to project (or epic to epic, using SAFe terminology). Theo van der Westhuizen, who played a pivotal role in the transformation process, referred to the new practice as servant leadership.

\section{Training Initiative}

Achieving changes in attitudes towards work practices was neither easy nor immediate. As the group increasingly organized into agile teams, individuals--particularly the group's many project managers--that had previously managed through command-and-control directives needed to be moved to positions requiring an entirely different approach. To accomplish this, a major training and retraining initiative was needed. The initiative involved a variety of different types of training that included:

- Workshops on agile processes and servant leadership.

- Extended retraining courses for individuals whose job category no longer existed. For example, project managers that demonstrated the required aptitude through testing could chose to be retrained as programmer/developers, at the bank's expense. Upon successfully completing retraining, they would be assigned new jobs at their prior pay levels.

- Encouragement of outside certifications.

The many ways in which training was incorporated into the shift in cultural priorities is illustrated in Exhibit 14.

\section{Moving Forward with the Transformation}

The initial results of the transformation to SAFe have been impressive. For example, as shown in Exhibit 15, within the ATM group the time to release an application has dropped from 700 days to 30 days, 
productivity has risen by $50 \%$ and the cost per function point has dropped by $70 \%$. Accompanying this has been substantial increases in the group's overall Organizational Health Index with substantial rises in both 2015 and 2016. Langerman has also recently learned that the indicator has continued to rise, albeit by $1 \%$, in 2017 . This, in itself, was a remarkable achievement since that indicator would typically be expected to drop temporarily during periods of rapid organizational change, such as the IT Group was experiencing. Even more remarkable, the group has managed this transformation at a time when its budget was being trimmed to the tune of $\$ 300$ million (over 3 billion Rand).

The rollout of SAFe and NWOW was also proceeding rapidly, as shown in Exhibit 16. Already, well over half the development staff has been organized into feature teams. By the end of 2017, it was expected that $90 \%$ of the group would be applying the SAFe approach, with the process reaching completion in 2018.

Theo van der Westhuizen, who played a pivotal role in the transformation process, sounded a cautionary note, however. He noted that change processes typically followed a pattern of enthusiasm similar to Gartner's well-known hype cycle (see Exhibit 17). Inevitably, he felt, there would be a backlash to the transformation. The danger was that this backlash could undermine the progress that has been made.

There were certainly some potential reasons for this concern. These were largely cultural in nature. Under the old processes, project managers had a certain status within the organization. They had people working for them, a clear title and a standard for their activities, defined by the Project Management Institute. All of this changed under the SAFe model. The authority associated with command-and-control leadership would need to be abandoned. Formal position titles were largely supplanted by roles that could be transitory in nature. Orders and instructions were replaced by facilitation and coaching. Many of these individuals, at least at first, would long for the "good old days".

Even more challenging would be achieving long term buy in from higher levels of management. Whereas the processes through which projects entered the development queue had been somewhat opaque under the old system; the new system required transparent prioritization. Like most organizations, business units tended to operate in silos. This prioritization process could easily result in one business unit competing with other units for position in the queue. There was also the matter of the dynamics of the workplace. While traditional banking standards of dress--suits, blue shirts and ties for men, carefully prescribed dresses for women--had long been abandoned at Standard Bank; the new relaxed look of the group could be disconcerting to old-timers. No longer could status be determined by appearance. In parallel to this, the team-based work patterns and high levels of engagement entailed by the SAFe led to a workspace where individuals were frequently in motion and rarely chained to their desks. Would this new culture persist if Langerman's group--which he had frequently referred to as the "Vortex of Fluff”--ceased or scaled back its efforts to promote the transformation? Or would it revert to prior, familiar ways of work with which many in senior management had grown comfortable?

Van der Westhuizen advocated a model that he and the team developed for sustaining and promoting further transformation, shown in Exhibit 18. Under this model, change needed to be enabled at the cognitive level (headspace), through changes to the physical environment (structural space), in the way individuals communicated (interaction space) and in how they projected themselves (field space). Accompanying this, he had proposed an ambitious set of activities to achieve the needed changes. These activities included:

- Personal interventions

- Creation of specialized ceremony spaces

- Creating artifacts and acquiring information through a variety of sensing tools

- Incorporating ground rules for servant leadership into the organizational climate 
- Promoting “double loop” learning; continuously incorporating lessons about how we learn into future learning

- Coaching sessions

- Immersing executives into unfamiliar contexts to expand their perspectives

- Establishing a variety of academies to communicate these messages

Some of these activities would be costly, while others did not involve any additional direct cost. All of them, however, would involve the time of the staff participants involved. He justified their value by pointing to the success of the group's earlier facilitated activities. He pointed out that his servant leadership workshop currently had a two year backlog of individuals waiting to attend.

\section{The Decisions}

As Langerman thought about going forward, he was faced with recommending actions across a wide range of decisions. These included decisions that were both tactical and strategic in nature.

\section{Involvement of Outside Experts}

There was an ongoing debate within the bank regarding the role that outside experts, such as McKinsey, should play as the transformation moved forward. Up the current point, the group had derived considerable satisfaction from the degree to which it had achieved success on its own. This approach had also fostered a sense of ownership of the decisions that had been made.

The group did not operate in a vacuum, however. In much of the bank, the use of consultants was routine. These outsiders had been very effective in capturing complex ideas and presenting them in a manner that could be understood by key stakeholders. They could also be useful in moving across non-porous boundaries within the organization. Furthermore, since they were widely involved with firms in both banking and non-banking industries, they were often available to provide instruments (such as McKinsey’s OHI) and benchmark measures that were not available within the bank itself.

Of all the decisions he faced, this was--in many respects--the most structured. If consultants were to play a major role, they would need to be incorporated into the upcoming budget.

\section{Manage Rate and Direction of Transformation}

Over the past three years, change had been continuous and dramatic. Nevertheless, there remained much that needed to be done. The question facing Langerman was whether he should advocate pausing the changes being initiated for a while, thereby allowing the organization to catch up, or if the recommendation should be to continue or even accelerate the pace of change.

Complicating this choice was the fact that transformation was not a single construct. Over the past three years, changes had been made to the technologies employed by the group, the methods employed by the group, the climate of the bank (as exemplified by the physical layout, policies and organizational structure) and the culture experienced by the staff. To some degree, each of these could be addressed separately. Would it make sense, for example, to place more emphasis on culture for a while, given that such major changes had been made to methods and technologies? Langerman also recognized, however, the high level of interdependencies between these different aspects of the transformation. What could be done to keep them aligned? 


\section{Addressing Tradeoffs}

In managing the transformation, there was also the matter of tradeoffs. A particularly common tradeoff, one experienced by nearly every technology activity, was that of quality vs. speed of delivery. Because the processes prior to the change had been so inefficient, over the past three years the group had been able to make progress in both directions simultaneously. As the new way of working becomes the standard practice, however, this was likely to change. If the bank pushed too hard to get new applications out quickly, the number of defects and problems was likely to rise. If, however, the bank emphasized getting each new application perfect before delivery, it would not only slow releases significantly, it would also tend to undermine the MVP philosophy that underpinned the lean-agile development process.

A particularly important related tradeoff was between the short-term and long-term. At the time of the case, the bank was aggressively trying to contain and reduce its IT budget. As was the case for the quality vs. timing tradeoff, the pre-transformation budget had been sufficiently bloated, so that it had been possible to reduce it even as the group engaged in full scale changes. For the future, however, initiatives such as the major training program proposed by van der Westhuizen, and a variety of plans to replace old hardware and systems with more modern capabilities would involve substantial hits to the current income statement in order to achieve future benefits. To what degree would the bank support such a tradeoff?

Langerman felt that significantly increasing the level of automation of development and delivery could significantly reduce the cost of achieving higher speed and quality. Automation was not a panacea, however, because it involved tradeoffs as well. Initially, it could be costly to develop and implement automated systems (the present vs. future tradeoff). Equally important, one of the key benefits of automation was in reducing the need for people. This reduction not only impacted the direct cost of staff, it also reduced the number of problems that could be attributed to human error. In South Africa, however, providing employment was considered an important social good that an organization was expected to provide. To what extent should he advocate moving aggressively towards a goal that seemed to work against the goal of providing employment?

\section{Expanding Across Standard Bank}

Just recently, Langerman had come across another choice he needed to consider. Recently, he had been approached by several areas--Finance, Human Resources (HR) and Marketing--that had been intrigued by the IT Group's successful transformation. They wondered if the types of practice and culture changes that had been achieved by the group might be adapted to their areas.

Langerman recognized that this could be a big win for the bank. Even with 6000 employees, the IT area only represented a small fraction--under 15\%--of the bank's total staff. If the NWOW could be adapted across the bank, particularly to include the huge salesforce and branch staff, the results could be staggering. It might also provide for more seamless communication between IT and the other areas of the bank. The "if" involved was significant, however. Most of the practices associated with NWOW had been tested principally in the area of software development. How likely would it be that similar benefits could be realized if generalized to very different types of work? And if enthusiasm for this experiment was high, how much would it distract from the activities of the group itself? 


\section{Biographies}

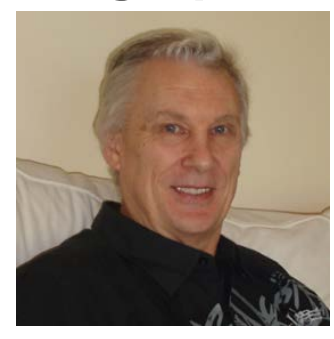

Kevin Johnston is a Professor and Head of Department of the Department of Information Systems at the University of Cape Town, South Africa, and a visiting Professor at the University of Pforzheim, Germany. He holds a PhD in Information Systems from the University of Cape Town. His principal research areas are ICT strategy and management, IS educational issues, Social and Networking systems, Emerging technology, and Entrepreneurship.

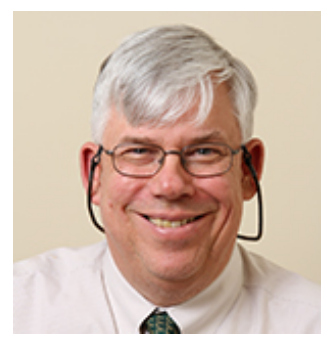

Grandon Gill is a Professor in the Information Systems and Decision Sciences department at the University of South Florida. He holds a doctorate in Management Information Systems from Harvard Business School, where he also received his M.B.A. His principal research areas are the impacts of complexity on decisionmaking, the diffusion of academic research findings and applying the case method to STEM education. He is currently Editor-in-Chief of the Journal of IT Education: Discussion Cases and of the Muma Business Review. 


\section{Exhibit 1: Map of South Africa}

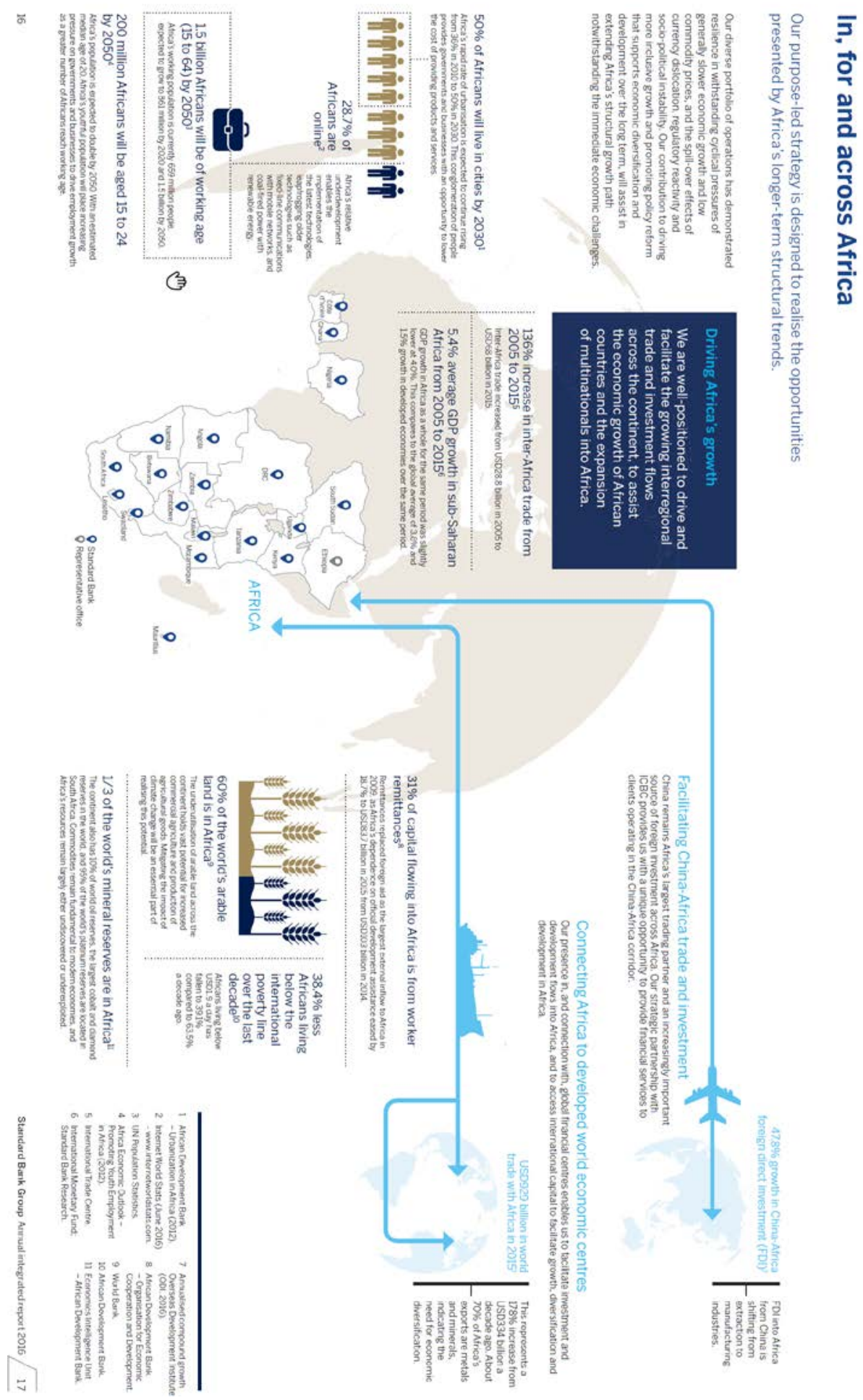

Source: 2016 Standard Bank Annual Report 


\section{Exhibit 2: Standard Bank Facts}

\section{Standard bank is The leading financial institution in Africa}

152-year history in Africa
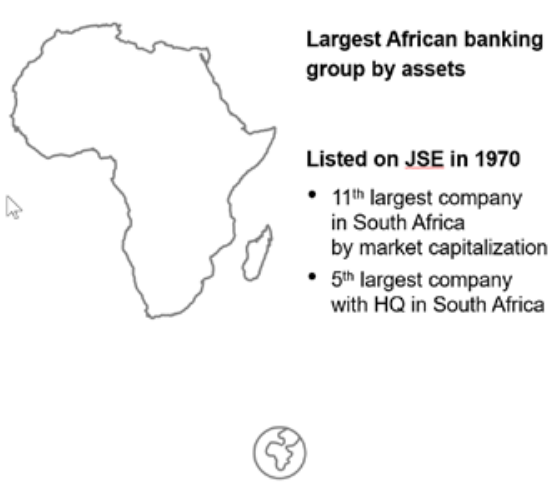

Offer a range of corporate, business and personal banking and financial services in $\mathbf{2 0}$ countries in Africa as well as abroad
Contribution to headline earnings, 2015
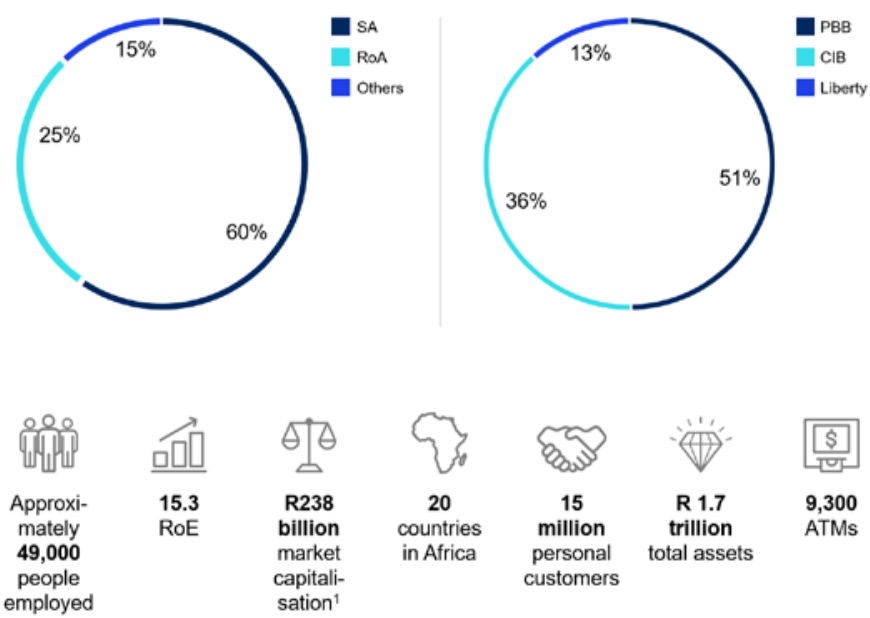

$\begin{array}{cc}\text { 15.3 } & \begin{array}{c}\text { R238 } \\ \text { billion } \\ \text { market } \\ \text { capitali- } \\ \text { sation' }\end{array}\end{array}$
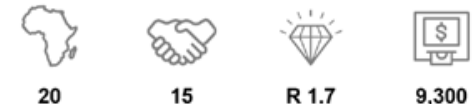

20

countries

in Africa

sation 1

million
personal trillion
total assets

personal total assets

Source: Standard Bank/McKinsey presentation 


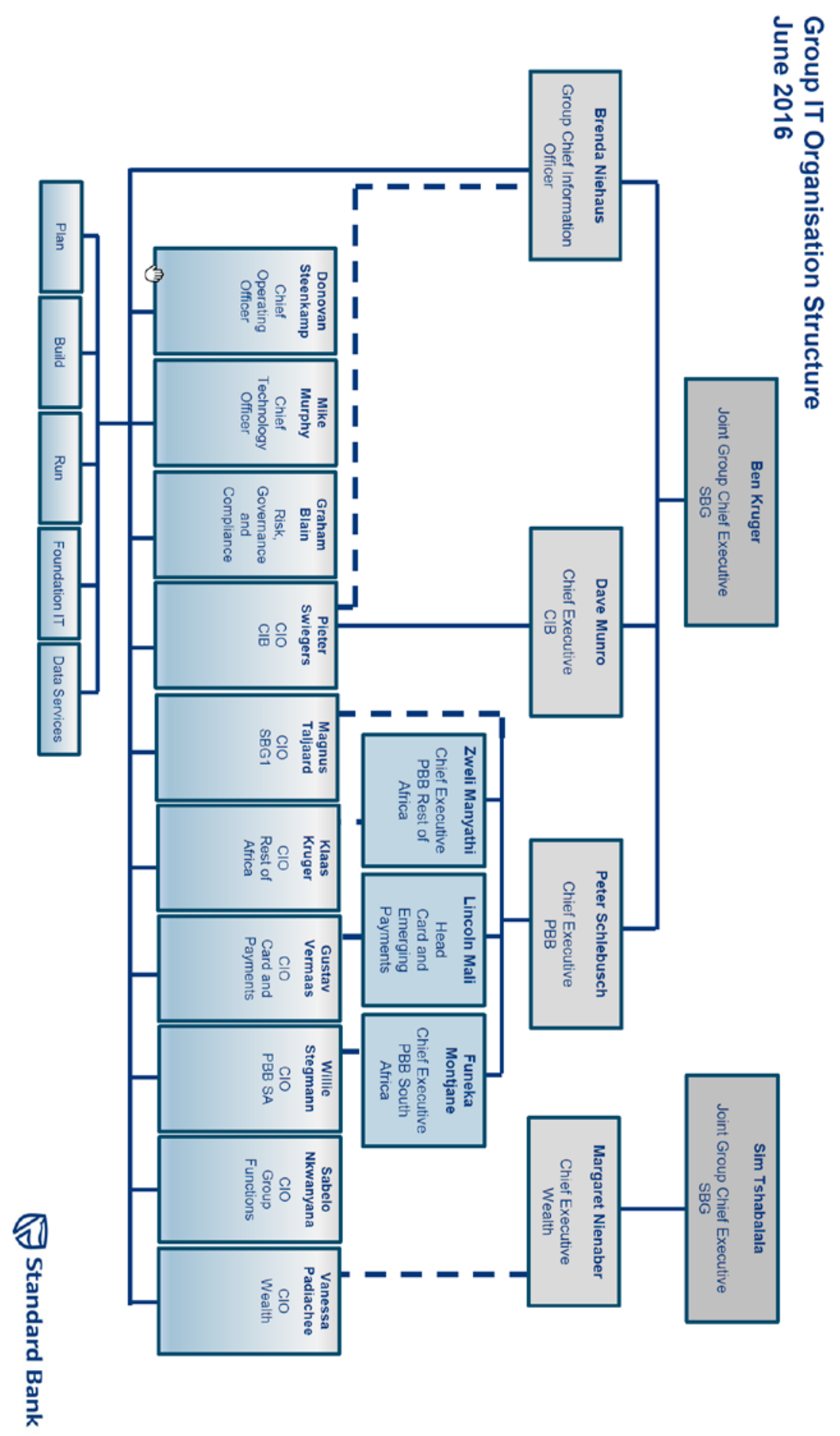

Source: Standard Bank internal document 


\section{Exhibit 4: Typical Systems Development Lifecycle}

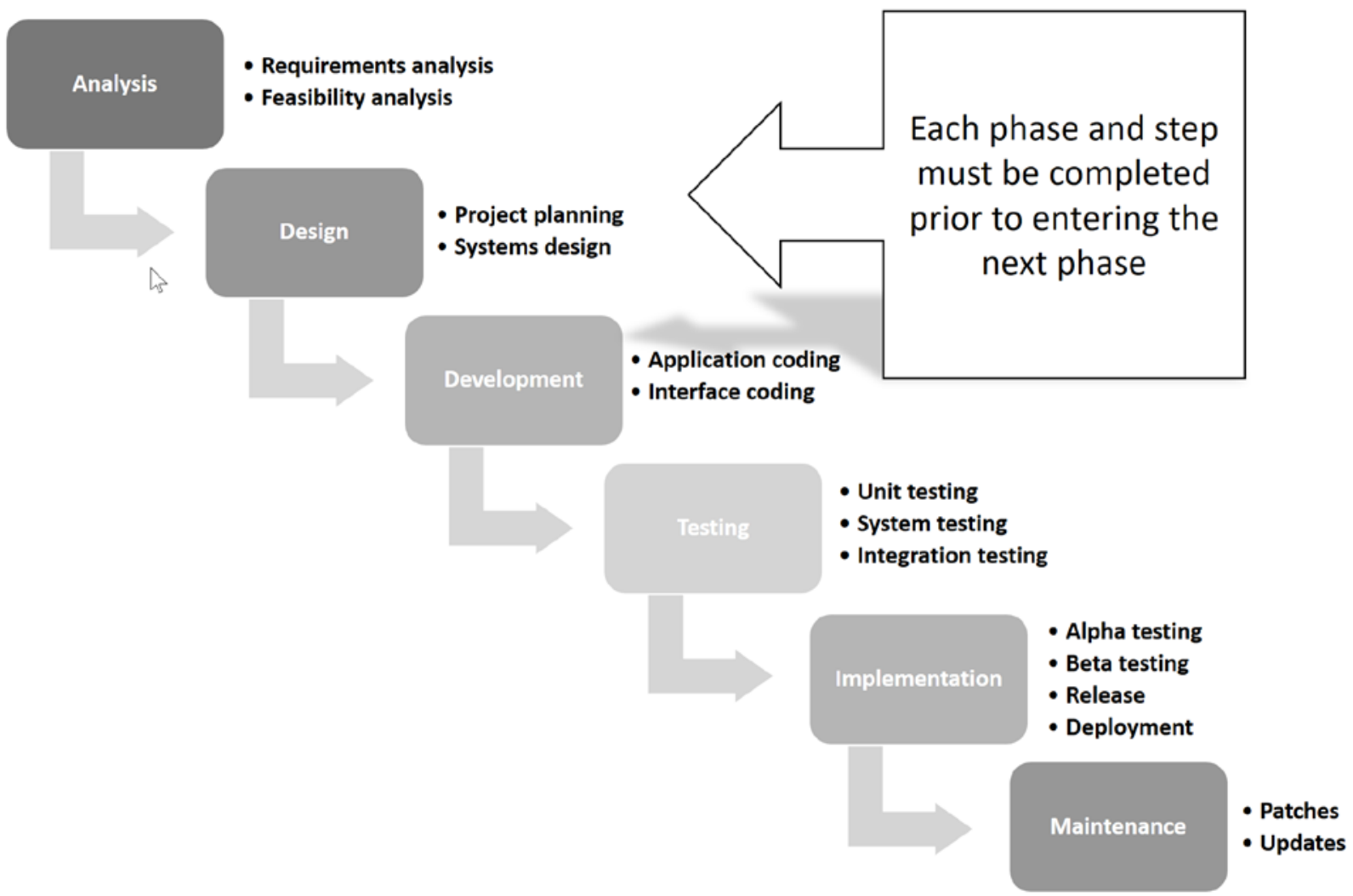

Source: Created by case writer 


\section{Exhibit 5: Problems Encountered by IT Group Pre-Transformation}

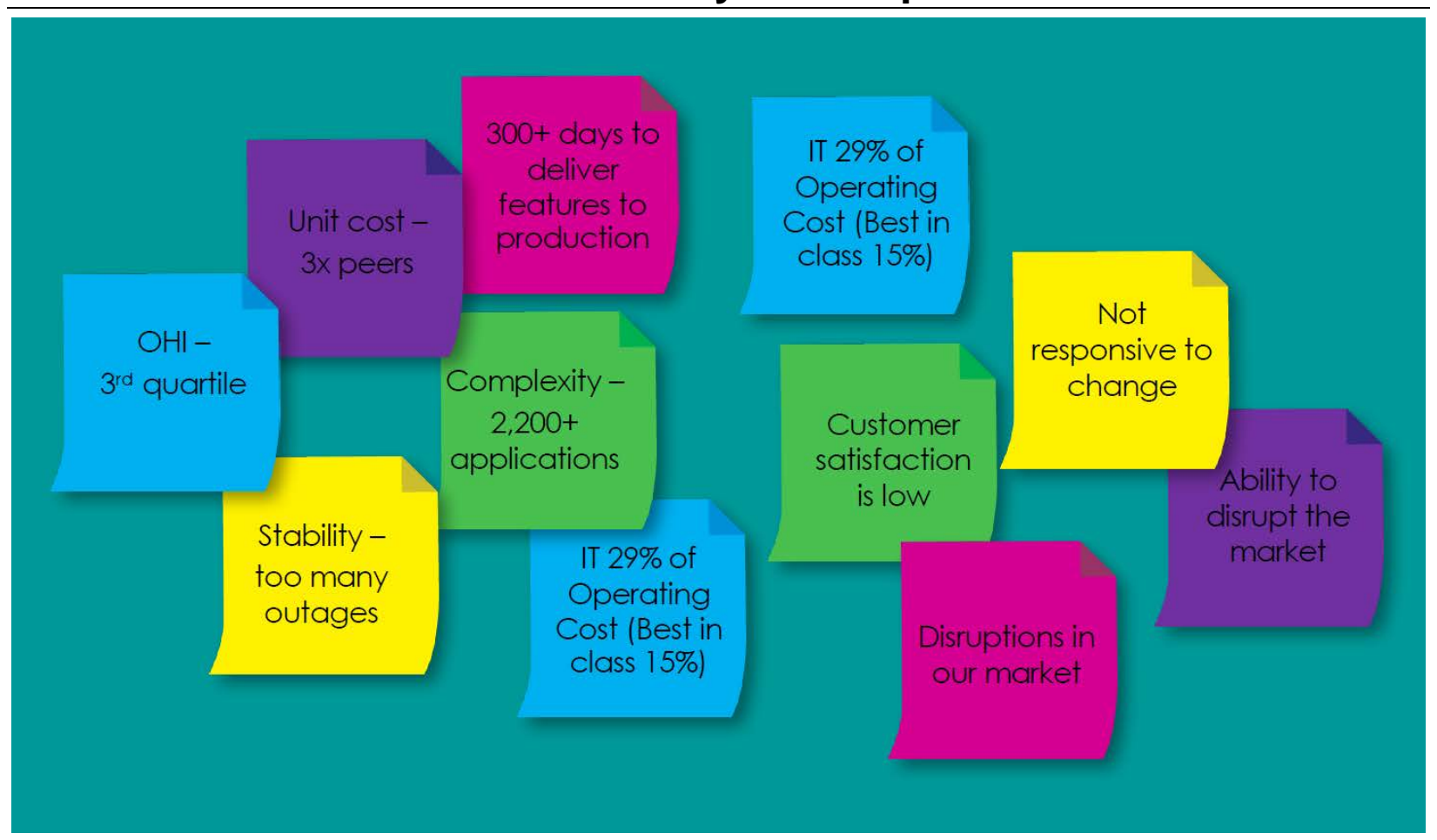

Source: Standard Bank internal document 


\section{Exhibit 6: SDLC Process Sticky Notes}

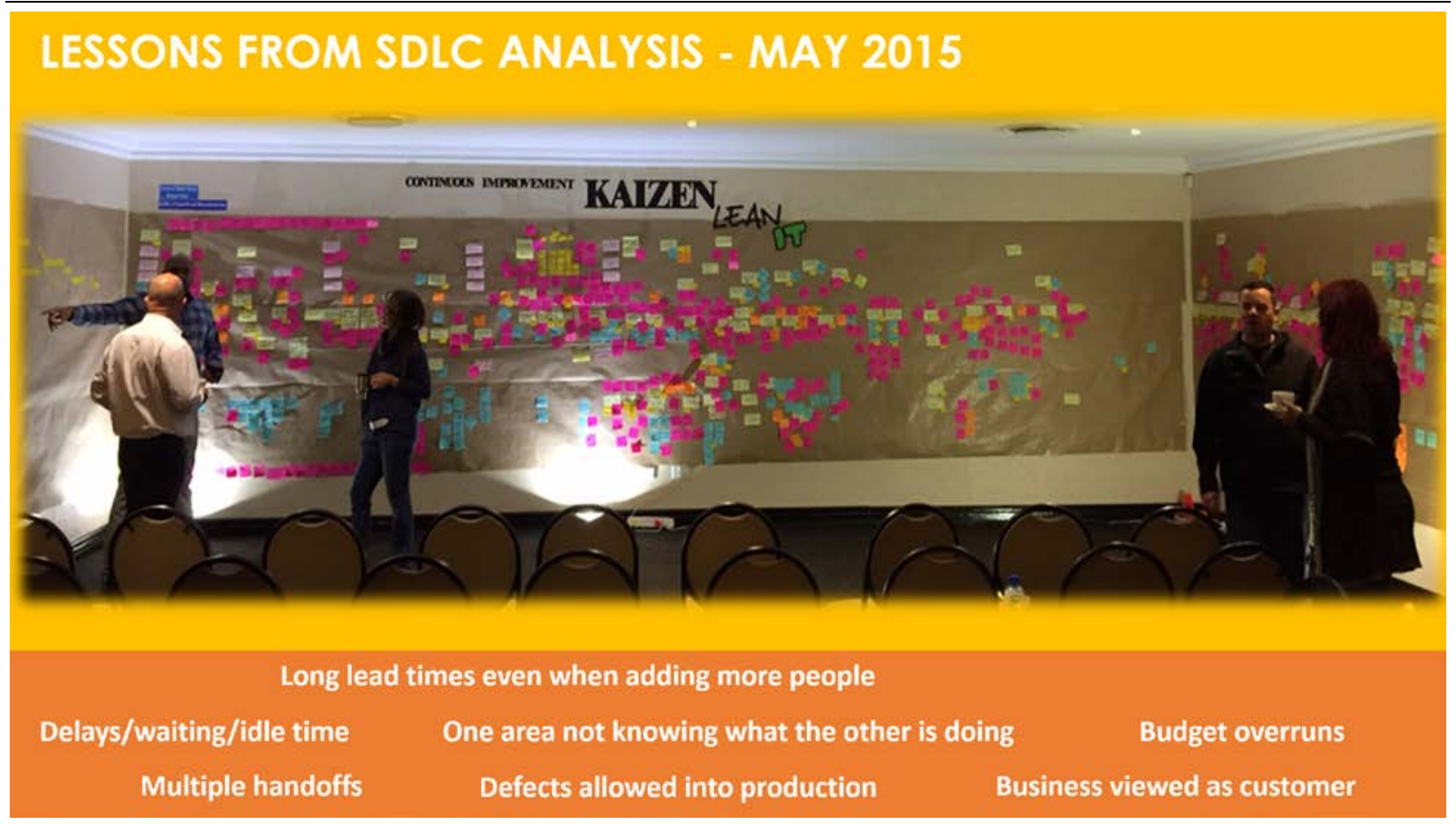

Source: Standard Bank internal document 


\section{Exhibit 7: Overview of SAFe Framework}

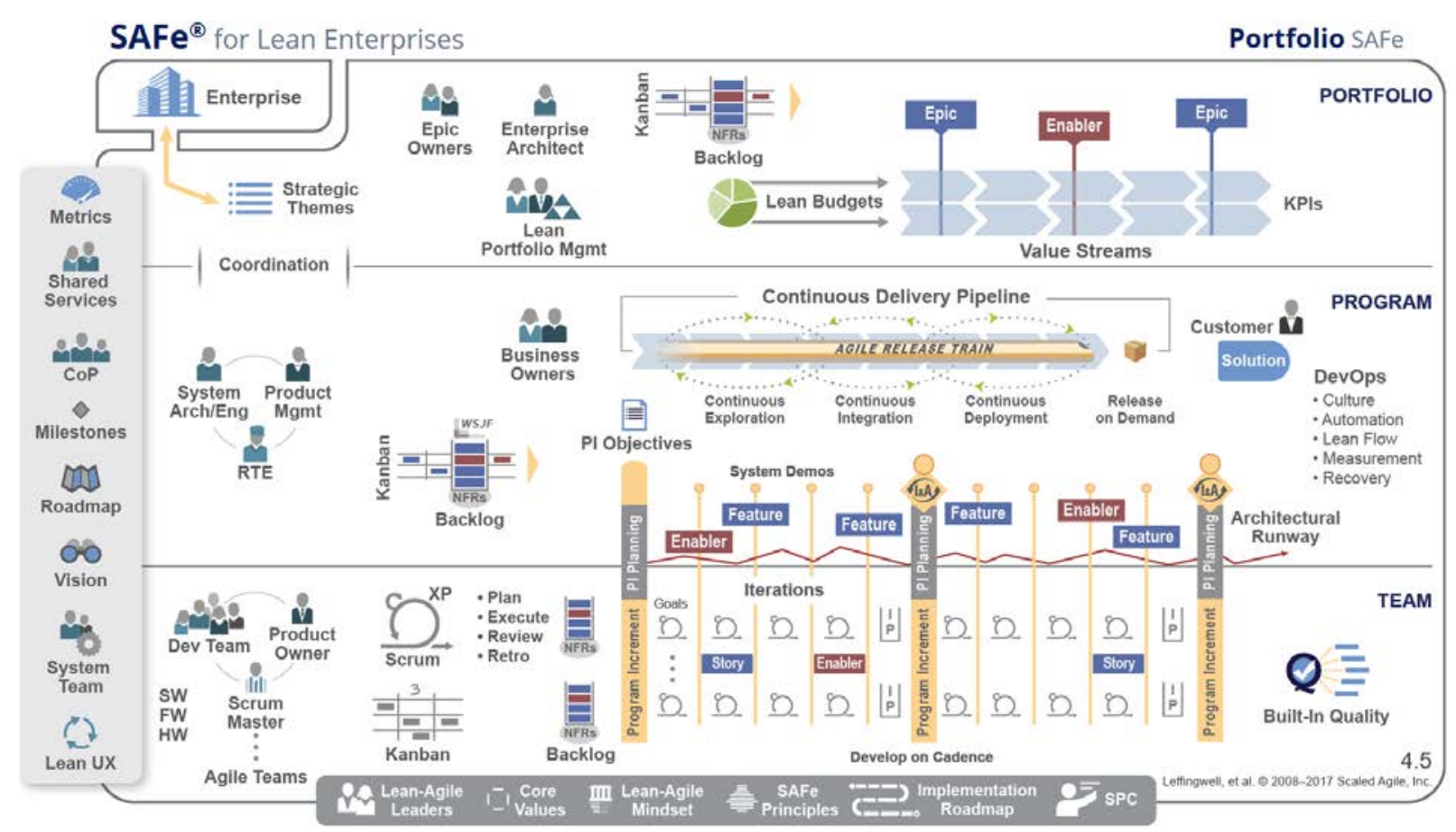

Source: http://www.scaledagileframework.com/ (Portfolio model, version 4.5) 


\section{Exhibit 8: Nine Principles of SAFe}

\section{SAFe is principles-based and aligned to Lean \& Agile general principles:}

1. Take an economic view

2. Apply systems thinking

3. Assume variability; presenve options

4. Build incrementally with fast, integrated leaming cycles

5. Ba se milestones on objective evaluation of working systems

6. Visualise and limit WIP, reduce batc $h$ sizes, and manage queue lengths

7. Apply cadence; synchronize with cross-doma in planning

8. Unlock the intrinsic motivation of knowledge workers

9. Decentralise decision-making

Source: Standard Bank internal document 


\section{Exhibit 9: The SAFe Framework Simplified}

\section{MOVING TO AGILE AT SCALE}

The SAFe Framework simplified

\begin{tabular}{l|l} 
PORTFOLIO LEVEL & Portfolio Kanban System
\end{tabular}

EPIC BUSINESS CASE

\begin{tabular}{|c|c|c|c|c|}
\hline FUNNEL & REVIEW & ANALYSIS & $\begin{array}{c}\text { PORTFOLIO } \\
\text { BACKLOG }\end{array}$ & IMPLEMENTING \\
\hline & & & & \\
\hline & & & \\
\hline & & \\
\hline
\end{tabular}

PROGRAM LEVEL

PROGRAM

BACKLOG

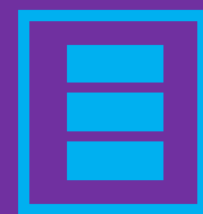

FEATURE (RELEASABLE)
AGILE RELEASE TRAIN

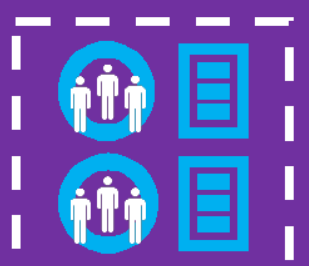

-
PRODUCT INCREMENT

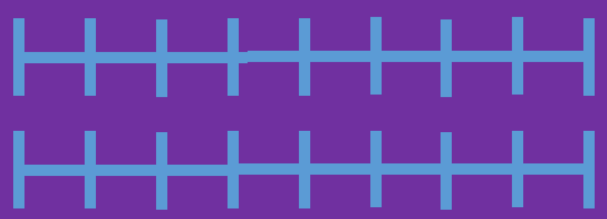

(8 - 12 WEEKS)

TEAM LEVEL

AGILE TEAM

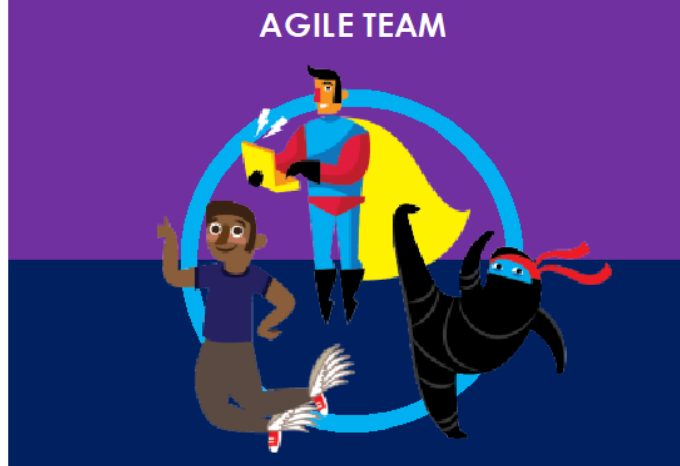

TEAM BACKLOG

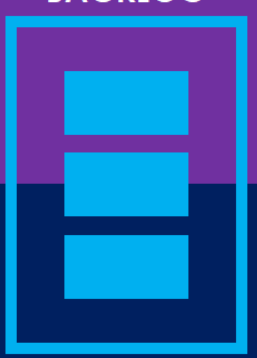

STORY (IESTABLE)
SPRINT

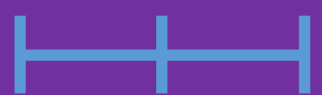

(2- 3

WEEKS)

Source: Standard Bank internal document 
Exhibit 10: Flow vs. Resource Utilization

\section{FIRST OPTIMISE FLOW, THEN RESOURCE UITILISATION}

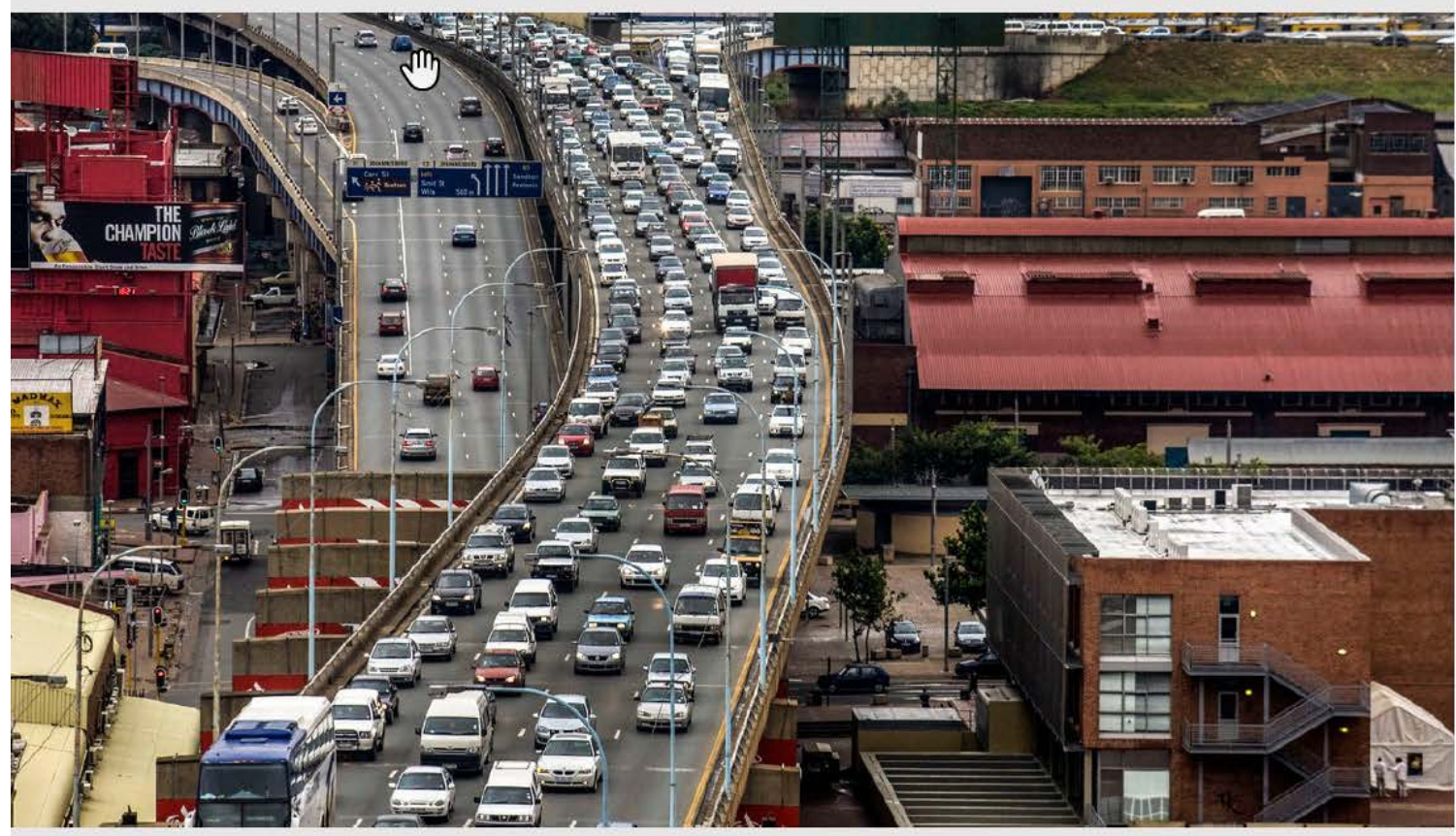

Notes

When resource utilisation (the highway on the right) is at $100 \%$, flow stops! First get the flow right, then begin improving resource utilisation. Resource utilisation should however never reach $100 \%$.

NWOW

Source: Standard Bank internal presentation 


\section{Exhibit 11: Organizing Framework for Achieving "New Ways of Working"}

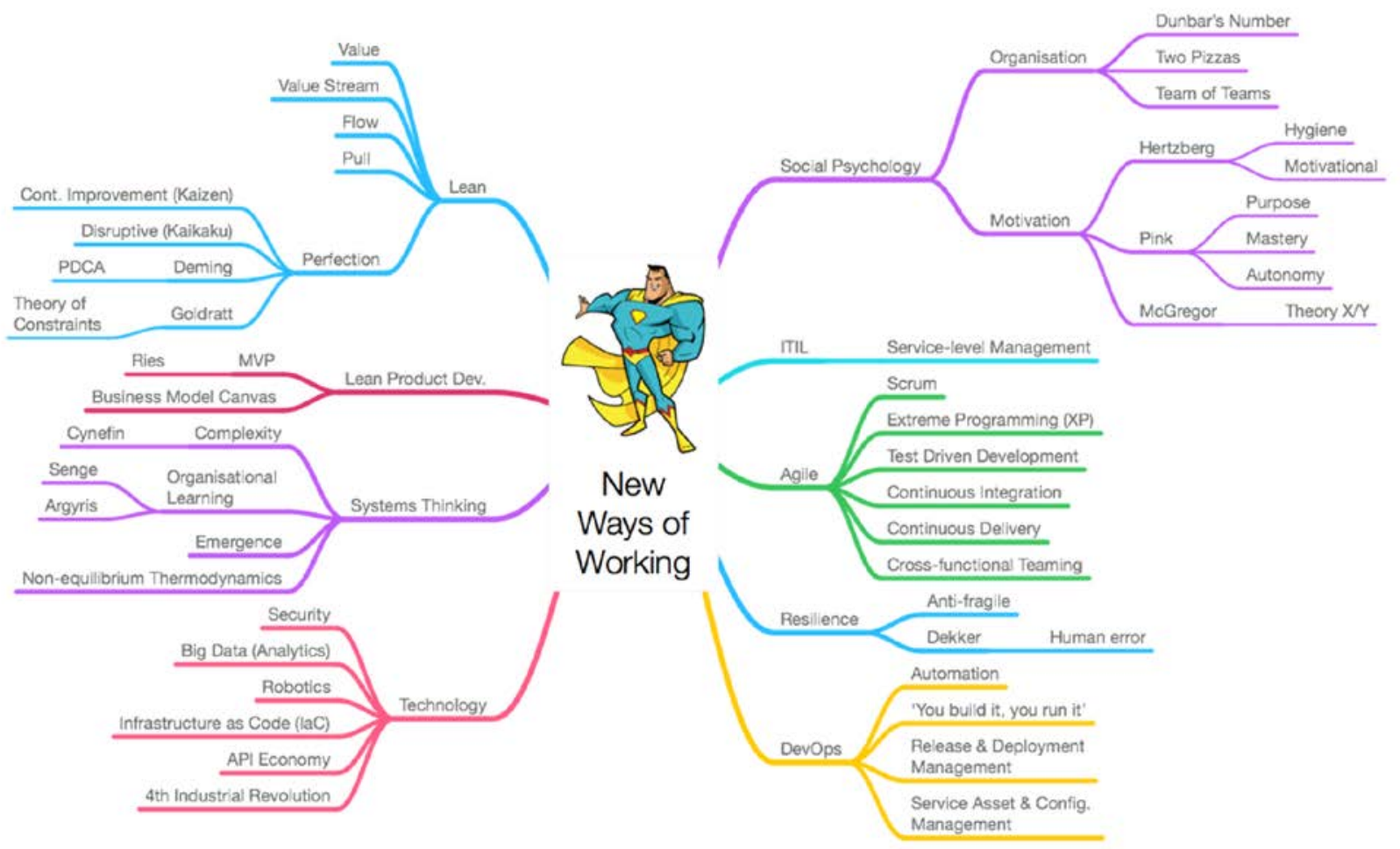

Source: Standard Bank internal presentation 


\section{Exhibit 12: Agile \& Lean Principles}

\section{NWOW IS BUILT ON LEAN \& AGILE PRINCIPLES}

Lean Principles

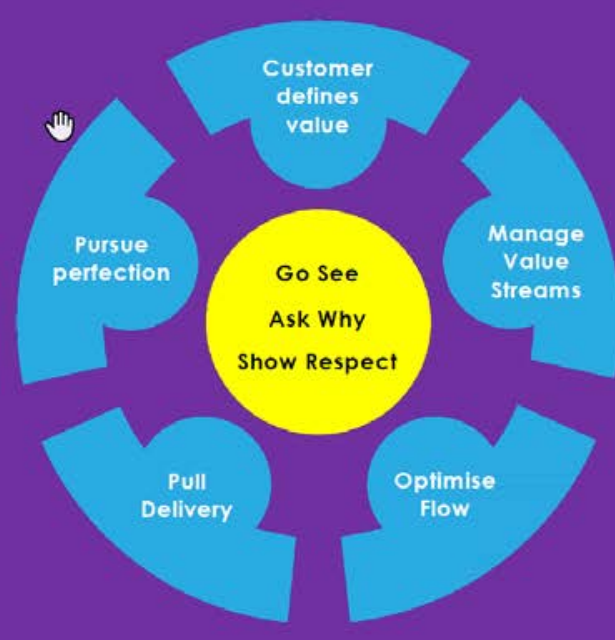

\section{Agile Principles}

1. Our highest priority is to satisfy the customer through early and continuous delivery of valuable software.

2. Welcome changing requirements, even late in development. Agile processes harness change for the customer's competitive advantage.

3. Deliver working software frequently, from a couple of weeks to a couple of months, with a preference to the shorter timescale.

4. Business people and developers must work together daily throughout the project.

5. Build projects around motivated individuals. Give them the environment and support they need and trust them to get the job done.

6. The most efficient and effective method of conveying information to and within a development team is face-ło-face conversation.

7. Working software is the primary measure of progress.

8. Agile processes promote sustainable development. The sponsors, developers, and users should be able to maintain a constant pace indefinitely.

9. Continuous attention to technical excellence and good design enhances agility.

10.Simplicity--the art of maximizing the amount of work not done--is essential.

11.The best architectures, requirements, and designs emerge from self-organizing teams.

12. At regular intervals, the team reflects on how to become more effective, then funes and adjusts its behaviour accordingly.

Source: Standard Bank internal document 


\section{Exhibit 13: Principles of Self-Regulating Teams}

Achieved through the Team Stand-up

iiv. Regular session with the whole team

- Team-led discussion

- Short and to the point

- Question 1: Are we ahead or behind?

- Question 2: Are we getting better or worse?

- Identify obstacles and assign responsibility

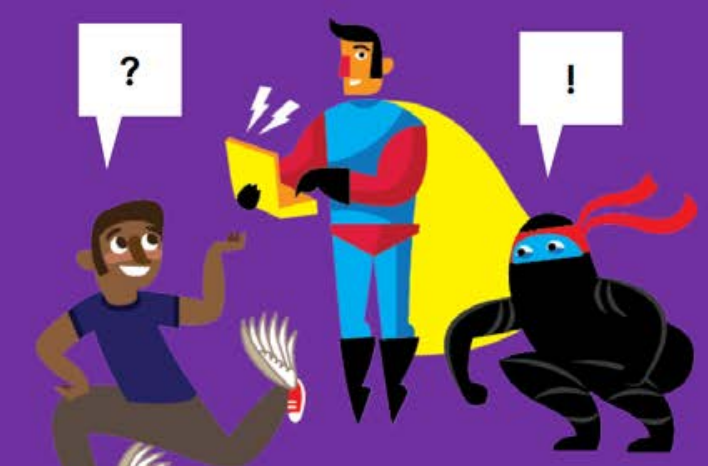

- Fosters continuous improvement

Source: Standard Bank internal document 


\section{Exhibit 14: Role of Training in Changing Cultural Priorities}

\section{Cultural Priorities (Q4 2016)}

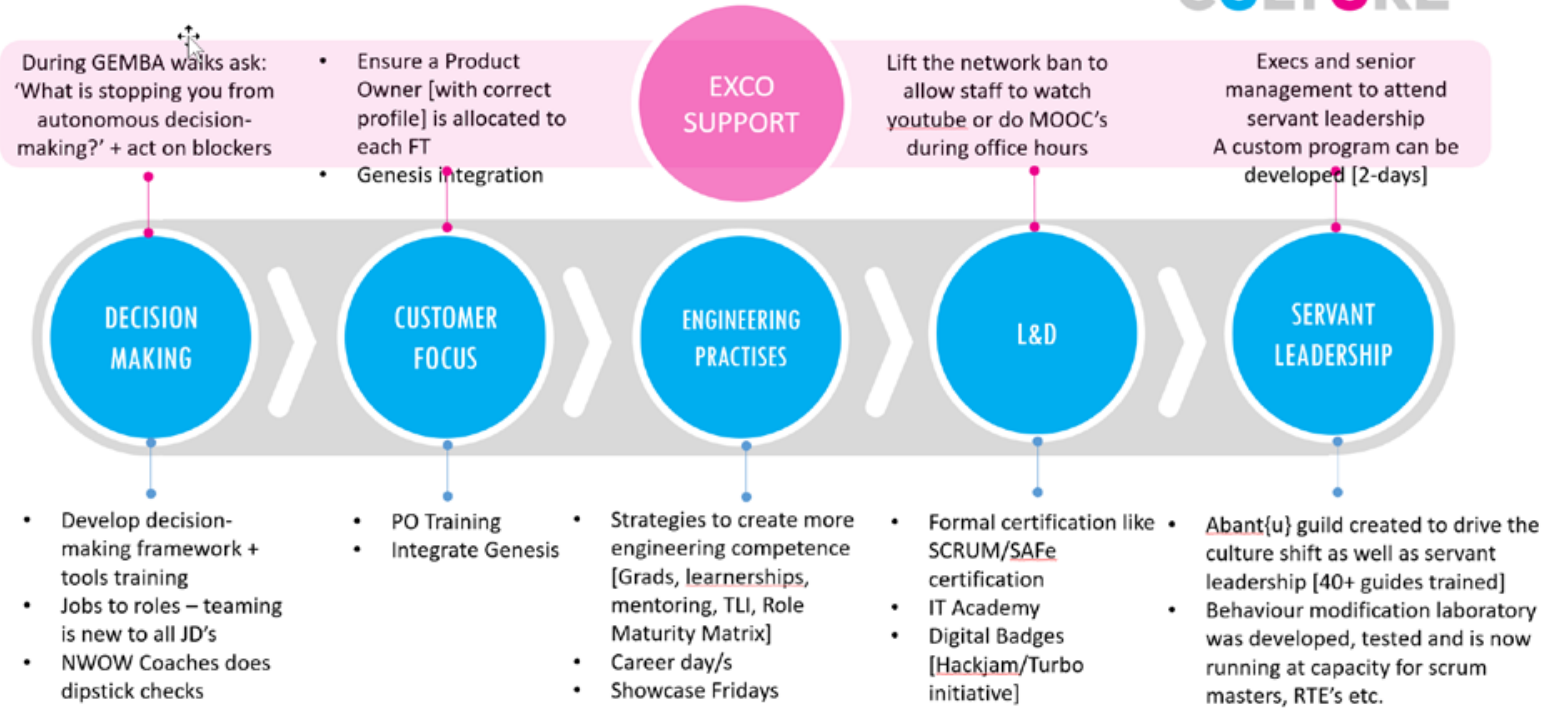

Source: Standard Bank internal document 


\section{Exhibit 15: Examples of Standard Bank Results from Transformation}

Agile@Scale is a key component to achieve our objectives and has already delivered significant benefits

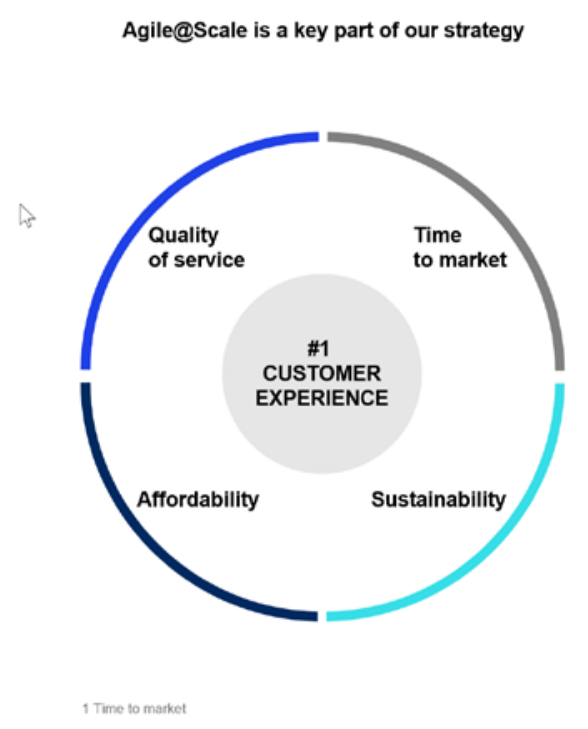

\begin{tabular}{l} 
Impact \\
Improved \\
efficiency \\
and cost \\
of service \\
delivery \\
\\
Improved \\
organisational \\
health \\
\hline \\
Sustainability \\
and leadership
\end{tabular}

Example results

Agile development within ATM team

$\begin{array}{llll}\text { Pre-pilot } & 700 & 30 & \text { Post-pilot } \\ \text { TTM } & & \end{array}$

TTM days days TTM

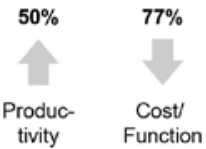

Group IT OHI results
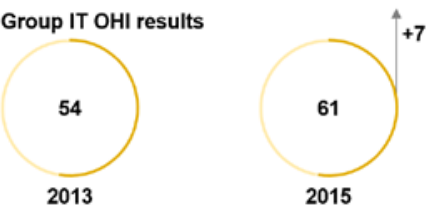

tivity

SOURCE: Standerd Bank - PROPRIETARY AND CONFIDENTIAL

Developed people by

(स)?

Hosting servant

leadership
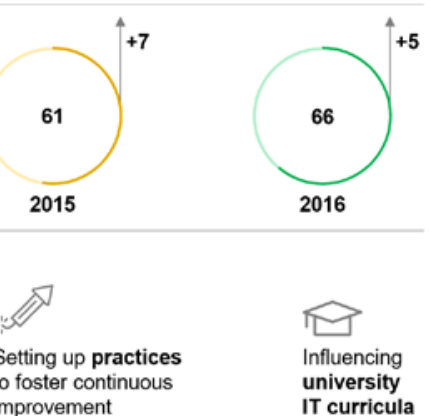

2016

Source: Standard Bank/McKinsey presentation 


\section{Exhibit 16: Status of Roll Out}

We continue to transform the organisation with an ambitious three year rollout plan

\begin{tabular}{|c|c|c|c|}
\hline & 2016 & 2017 & 2018 \\
\hline Design & $\begin{array}{l}\text { Designed agile } \\
\text { organisation bottom-up } \\
\text { with } \sim 2000 \text { FTEs }\end{array}$ & $\begin{array}{l}\text { Implemented } \\
\text { the new design }\end{array}$ & $\begin{array}{l}\text { Streamline engineering, } \\
\text { infrastructure, } \\
\text { UX and design uniformity } \\
\text { across all teams }\end{array}$ \\
\hline Teams & $\begin{array}{l}60 \% \text { of teams } \\
\text { transferred } \\
\text { to Feature Teams }\end{array}$ & 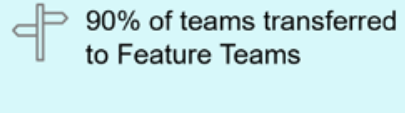 & $\widehat{8880} \begin{array}{l}100 \% \text { conversion } \\
\text { to Feature Teams }\end{array}$ \\
\hline Capabilities & $\begin{array}{l}\text { Used basic DevOps and } \\
\text { Agile collaboration tools }\end{array}$ & $\begin{array}{l}\text { Modularised architecture } \\
\text { and automated } \\
\text { deployment }\end{array}$ & $\begin{array}{l}\text { Next Generation } \\
\text { Infrastructure across } \\
\text { all Feature Teams }\end{array}$ \\
\hline $\begin{array}{l}\text { Business } \\
\text { Integration }\end{array}$ & \begin{aligned} &$\square \multicolumn{1}{c}{$ Appointed Business } \\
&$\square \square$ employees into Feature \\
& Team roles (PO') \end{aligned} & $\approx=\begin{array}{l}\text { Assignment of POs from } \\
\text { business for most teams }\end{array}$ & $\begin{array}{l}\Omega^{2} \mathrm{C} \text { Full PO assignment, } \\
\text { DevOps and } \\
\text { agile practices adopted }\end{array}$ \\
\hline $\begin{array}{l}1 \text { Product Owner } \\
\text { SoURCE: Standard Bank- }\end{array}$ & PROPRIETARY AND CONFIDENTIAL & & Mckinsey \& Company \\
\hline
\end{tabular}

Source: Standard Bank/McKinsey presentation 


\section{Exhibit 17: Typical Organizational Change Cycle}

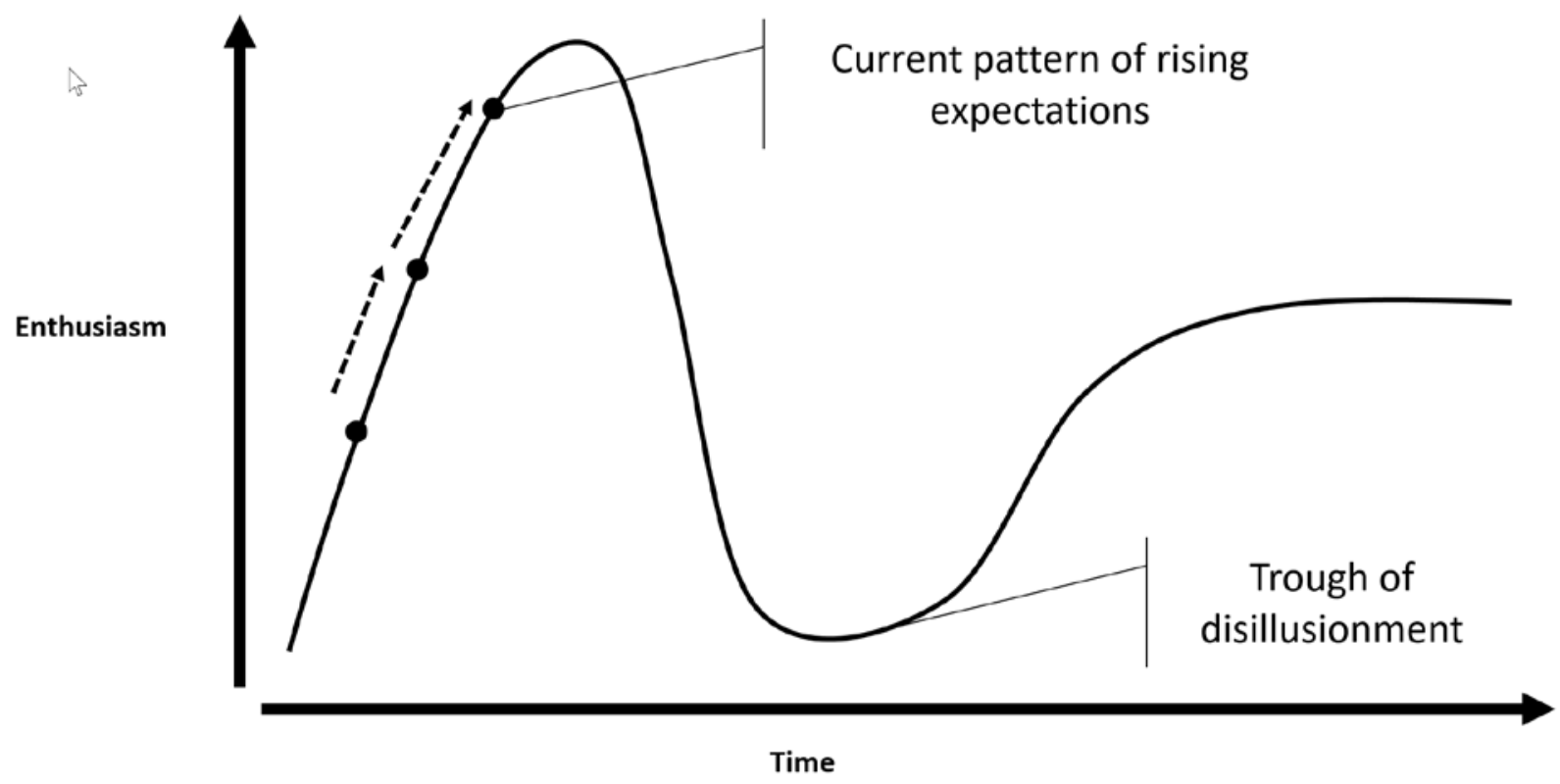

Source: Prepared by case writer (inspired by Gartner Hype Cycle) 


\section{INVITATION TO SHIFT MODEL}

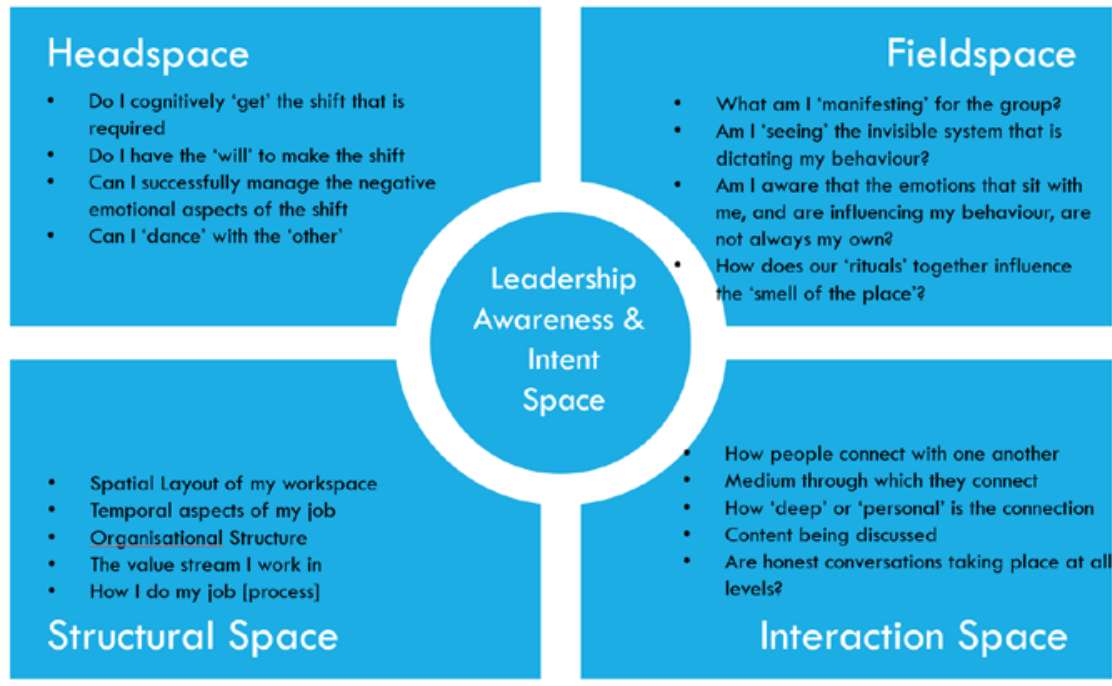

The five spaces on the model depicts areas that need attention to allow employees to make the shift in the direction of Leadership's intent [New IT].

A lack of focus or intervention/s in any of these spaces may delay and eventually negate the required shift.

Source: Provided to case writers by Theo van der Westhuizen 